\title{
Dangerous to mix: culture and politics in a traditional circumcision in South Africa.
}

\author{
Meel Banwari
}

Walter Sisulu University, Forensic Medicine

\begin{abstract}
Background: Traditional circumcision (initiation) is an integral part of the Xhosa speaking communities. Circumcision is the first step towards manhood. It involves a number of cultural, religious, legal and ethical issues, which in terms of the constitution of the Republic of South Africa, are rights that must be protected.

Objective: To highlight the problem of circumcision related death in South Africa.

Case Report: This case report examines a 16- year boy who had died as result of botched circumcision by an unqualified traditional surgeon. He kept the boy in his custody despite his serious illness. He applied a tight bandage to control the bleeding, resulting in gangrene of the penis followed by septicemia. The histories, postmortem findings, cause of death and medico- legal and social aspects have been discussed in this manuscript.

Conclusion: There are unacceptable deaths related with circumcision in South Africa. The right to life cannot be sacrificed at the altar of culture and politics.
\end{abstract}

Keywords: Circumcision, initiation, religion, culture and politics.

DOI: http://dx.doi.org/10.4314/ahs.v15i1.38

\section{Introduction}

The origination of male circumcision is not known with certainty but has been existent from time immemorial. The widespread practice of the tradition of circumcision and initiation rites throughout Africa, and the frequent resemblance between details of ceremonial procedure in areas thousands of miles apart, indicate that the circumcision ritual has an old tradition behind it and in its present form is the result of a long process of development ${ }^{1}$. Traditional circumcision involves issues of culture and religion. All over the world male circumcision has its roots deep in the structure of society. Far from being a simple technical act, even when performed in medical settings, it is a practice which carries with it a whole host of social meanings ${ }^{2}$.

\section{Corresponding author: \\ Meel Banwari \\ Walter Sisulu University, \\ Forensic Medicine \\ Email: bmeel@wsu.ac.za}

The ritual of male circumcision is performed at specific periods in life with the main purpose of integrating the male child into the society according to cultural norms ${ }^{3}$. It is among the most secretive and sacred of rites practised by the Xhosa speaking people of South Africa. Recently, the alarming rate of deaths and injuries among initiates has led to the spotlight of media attention and government regulation being focused on traditional circumcision ${ }^{4}$. Circumcision undertaken in non-clinical settings can have significant risks of serious adverse consequences, including death ${ }^{5}$. Over the last two decades, following ritual male circumcision, thousands of youth have been admitted to hospitals, hundreds have undergone penile amputations and hundreds have died in Eastern Cape Province of South Africa ${ }^{6}$.

The incidence of circumcision related complications and fatalities have remained virtually unchanged between 2001 and $2006^{7}$. A community based study carried out by the author showed that about $67 \%$ were unaware of risks of traditional surgery and $16 \%$ unsure about any potential risk. Only 17\% knew about risks associated with it. Sixty-three percent favoured traditional surgeons and 13\% medical practitioners ${ }^{8}$. It has come to our attention that there were at least 20 young men who died in a number of schools within a short space of time. The fact that many young boys are circumcised without consent and knowledge of their parents creates a fertile ground for deaths, amputations 
nospitalization of initiates. This is an important aspect of our life that must not be left to soldiers of fortune who want to make money out of the tradition and at the expense of the lives of youngsters?

The ritual of traditional male circumcisions (initiation) of young adults goes back generations among Xhos people of South Africa. Xhosa tribe is committed to preserving the old cultural traditions ${ }^{8}$. Unqualified surgeons, negligent nurses, irresponsible parents and youth medically unfit for the hardships of initiation continue to contribute to tragic outcomes. It shows that the botched circumcisions are a public health hazard ${ }^{7}$. The purpose of this case report is to highlight the problem of circumcision related deaths in these areas.

\section{Case history}

TM, a 16-year school boy escaped from home to a lo-

al traditional surgeon for circumcision (initiation) in summer holidays. He had been convinced by his pe groups to go for a circumcision. He had stolen R150 from his parents and left home without permission of his parents. The traditional surgeon accepted him. He was circumcised along with other initiates. White clay was applied on his face and body. The bleeding from the wound failed to stop, then the surgeon applied bandage. On 4th day, he started feeling chills, and the body temperature rose. He became weak, and collapsed on 6th day of circumcision according to informants.

Family was informed about his death by the traditional surgeon. The family reported to police, and the police registered a case against the traditional surgeon and postmortem was conducted. An average built young boy was painted with white clay, and looked dehydrated on inspection (Photograph 1).
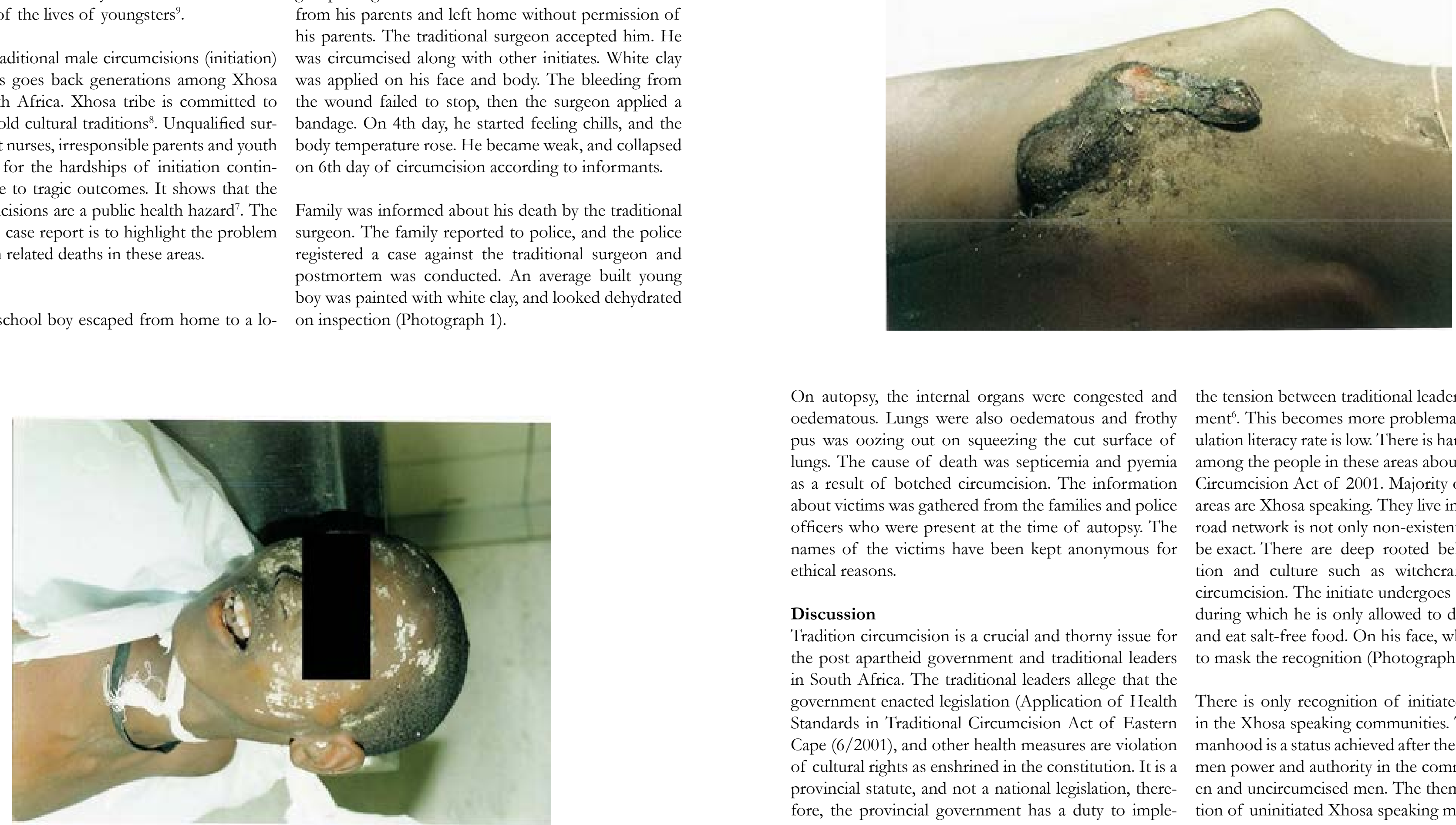

The skin on the shaft of penis was peeled off partly. It nis was fibrosed and shriveled, indicating that there was was a blackish dark necrosed penis. The glans of the pe- a sign of wound healing on palpation (Photograph 2).

On autopsy, the internal organs were congested and oedematous. Lungs were also oedematous and frothy pus was oozing out on squeezing the cut surface of lungs. The cause of death was septicemia and pyemia as a result of botched circumcision. The information about victims was gathered from the families and police officers who were present at the time of autopsy. The names of the victims have been kept anonymous for ethical reasons.

\section{Discussion}

Tradition circumcision is a crucial and thorny issue for the post apartheid government and traditional leaders in South Africa. The traditional leaders allege that the government enacted legislation (Application of Health Standards in Traditional Circumcision Act of Eastern Cape (6/2001), and other health measures are violation of cultural rights as enshrined in the constitution. It is a provincial statute, and not a national legislation, therefore, the provincial government has a duty to implement the Act firmly. There is also violation of rights of children under the Children's Act 38 of 2005, which is a national legislation, and is also applicable in death related with circumcisions. Under this Act, regulation require as no child ( $<16$ years of age), must not be allowed to go for circumcision.

The validity of the traditional leaders' challenge, that the crisis in the ritual should be seen in broader context than the tension between traditional leaders and the government $^{6}$. This becomes more problematic when the population literacy rate is low. There is hardly any awarenes among the people in these areas about existence of this Circumcision Act of 2001. Majority of people in these areas are Xhosa speaking. They live in rural areas where road network is not only non-existent but disastrous to be exact. There are deep rooted beliefs in the tradition and culture such as witchcraft, and traditiona circumcision. The initiate undergoes a seclusion period during which he is only allowed to drink muddy water and eat salt-free food. On his face, white clay is applied to mask the recognition (Photograph 1).

There is only recognition of initiated males as a man in the Xhosa speaking communities. The graduation manhood is a status achieved after the ritual that accords men power and authority in the community over women and uncircumcised men. The theme of marginalization of uninitiated Xhosa speaking males emerged with two categories, either rejection or lack of respect. The uninitiated men are rejected by the community, their own families, friends, and women ${ }^{10}$. TM was convinced by his peer group to get circumcised, as he sought to avoid the risk of marginalization in his community. The author has published a case report in 2004, which showed that a 25 years old boy had committed suicide as he was not being circumcised at his home. Not being circumcised after a certain age is considered inferior in 
the culture of the Xhosa speaking people ${ }^{11}$. Therefore, there is always a pressure on boys to get circumcised as soon as they reach a particular age. The age in terms of the Circumcision Act should be the 18 years and above. Parents do not allow the boys to go so early for circumcision and

they have to be sure that boys are mature before they go to these initiation schools. The boys tend to short-circuit the process by going to traditional surgeons without the knowledge of the parents. Informed Consent of the parents is a requirement in terms of the Circumcision Act of Eastern Cape in 2001. Surprisingly, the traditional surgeons accept them without any permission or consultation with their parents. This is a recipe for disaster as the scenario above seeks to illustrate the problem.

The dry gangrene led to necrosis of penis (Photograph 2), and resulted in the death of TM. The glan penis was reduced in size and showed that there was an amputation of distal part of penis, which led to severe bleeding. To control the bleeding by an unqualified nurse, he applied a tight bandage at the root of penis without knowing the consequences of tight bandage. This had led to stoppage of blood supply to the penis, and resulted into gangrene and necrosis. Traditional surgeons perform the procedure and, not uncommonly, amputation has to be the result. ${ }^{12}$ If TM was taken to hospital; probably his life and penis could have been saved by plastic surgery. There was a case report ${ }^{12}$, a 20 year man who sustained a midshaft penile amputation as a result of traditional circumcision, treated by modified penile - lengthening technique ${ }^{12}$. Unfortunately, TM was brought after his death to hospital. "In terms of the Traditional Circumcision Act of 2001, the traditional nurse is required to report any sign of illness According to the culture, a dead initiate is buried at the initiation school soon after his death. Although police is not undermining anyone's culture, people should remember that as police have an obligation to investigate any suspected unnatural death.

Conflict between government and traditional leaders is the major hurdle to solve the problem of circumcision related deaths. A recent study (2010) carried out by the author showed that the common causes of deaths were septicemia ( 9 patients; $36 \%$ ), pneumonia $(5 ; 20 \%)$, dehydration $(3 ; 12 \%)$, assault $(3 ; 12 \%)$, thromboembolism $(2 ; 8 \%)$, gangrene $(2 ; 8 \%)$ and congestive heart failure of an initiate to a medical officer as soon as possible ${ }^{13}$.
$(1 ; 4 \%)^{14}$. The Government is trying to use some scientific intervent such interventions as violation of cultural rights. The reasons for this rejection by traditional leaders are that these interventions tend to involve female professional who in terms of this custom should never come nea initiates. Women are not allowed to be involved in these processes at all.

The greed beyond all this is the generation of incom by traditional surgeons. The cost of traditional circumcision is between R3500 and R5000 which is shared partially by the family of the initiate ${ }^{8}$. The government wants that traditional leaders take care of their customs, but government cannot sit back and relax while people are dying ${ }^{15}$. The fact is that the government is either scared of traditional leaders to take any concrete steps to stop this disastrous practice. It is also possible that government lacks a strategy of working with traditional leaders to solve the problem.

Circumcision, an old custom in South Africa particularly in the Eastern Cape, has become a victim of politicization. It is dangerous to mix culture and politics, as experience has shown in the case of the Eastern Cape, which has resulted into a number of deaths that could not only be prevented, but that could be avoided in South Africa. Traditional circumcision has been a custom and practice among Xhosa speaking peoples. After 1994 as a result of democratic order, there has been a new set of new-comers into this long standing tradition. For instance, it has not been widespread practice in the Eastern parts of the Eastern Cape (Pondoland) for young men to get circumcised.

This tradition became stronger in those areas where systems were not available to assist people seeking to be part of the tradition. For example, when young boys want to go for circumcision, an older generation of men has to be part of the process. The purpose of having older men in the process is to ensure that the process is safe and that principles of manhood are trans ferred quite smoothly. In case of Eastern part of the Eastern Cape as well as in townships the process of traditional circumcision has been hijacked by the people who have not undergone the same custom. This result in deaths that are unnecessary in the Eastern Cape. These botched circumcisions do not occur in every part of the Eastern Cape. They occur in certain areas that are known to have the same problem every year; there
Politicians have become part of these processes but there has been no solution. Before 1994, politics was not part of the tradition. Traditional circumcision was actually the preserve of traditional communities. There was involvement of the traditional leaders who in fact are the custodians of this long standing tradition. Because of the involvement of traditional leaders the processes relating to circumcision were safe as traditional leaders always have a pool of counsellors around them who act as advisors to traditional leadership. There has always been adequate wisdom in relation to carrying out of the every year as a result of circumcision, but there is hardly any action on the part of government. In relation to noisemaking in this regard, the government has been more than efficient in terms of addressing good press conferences with all sorts of promises to address the problem. The emergence of unscrupulous traditional surgeons could have been as a result of politics and get rich quick schemes/mentality. Of course unemployment is part of the problem. People who do not have jobs can in some cases do anything including murdering others to survive. As the saying goes 'hungry stomach knows no truth'.

\section{Conclusion}

The cultural practices which are harmful to life contravene the norms of society, and must be changed sooner. In terms of the Constitution of the Republic of South Africa, everyone has a right to life. That right to life cannot be sacrificed at the altar of culture and politics. There is a serious health crisis that is going on in South Africa in relation to the ritual of circumcision. The government or traditional leaders, or both must take bold steps to resolve the problem and prevent these avoidable deaths and disabilities among Xhosa speaking boys in these areas. It always dangerous to mix culture with politics.

\section{References}

1. Wikipedia. History of male circumcision. Website: http://en.wikipedia.org/wiki/History_of_male_circumcision (accessed 22.07.2012).

2. Aggleton P. "Just a Snip"? A social History of Male Circumcision. Reproductive Health Matters 2007;15(29):15-21.

3. Mogotlane SM, Ntlanqulela JT, Ogunbanjo BG. Mortality and morbidity among traditionally circumcised Xhosa boys in the Eastern Cape Province, South custom. There are reports of deaths or serious injuries

frica. Curationis. 2004; 27(2):57-62.

'Vincent L. Boys will be boys': traditional Xhosa male circumcision, HIV and sexual socialization in contemporary South Africa. Cult Health Sex. 2008;10(5):43146.

5. Peltzer K, Nqeketo A, Petros G, Kanta X. Traditional circumcision during manhood initiation rituals in the Eastern Cape, South Africa: a pre-post intervention evaluation. BMC public Health. 2008;8:64.

6. Kepe T. 'Secrets' that kill: crisis, custodian and responsibility in ritual male circumcision in the Eastern cape, South Africa. Soc Sci Med. 2010; 70(5):729-35.

7. Meissner O, Buso DL. Traditional male circumcision in the Eastern Cape-scourge or blessing? $S$ Afr Med J. 2007;97(5):371-3.

8. Meel BL. Community perception of traditional circumcision in a sub-region of the Transkei, Eastern Cape, South Africa. SA Fam Pract.2005;47(6):58-59.

. Sapa. Eastern Cape circumcision deaths worry MEC Health24 News. Website: http://www.health24.com/ news/Health_services/1-4948,75391.asp(accessed 22.07.2012).

10. Mavundla TR, Netswera FG, Toth F, Bottoman B, Tenge S. How boys become dogs: stigmatization and marginalization of uninitiated Xhosa males in East London, South Africa. Qual Health Res. 2010;20(7):931-41. 11. Meel BL. Suicide among teenagers and young adults in the Transkei. Case reports. Anil Aggrawal's Internet Journal of Forensic Medicine and Toxicology, 2004; 5(2):1-4. Website: http://www.geradts.com/anil/ij/ vol_005_no_002/papers/paper003.html(accessed 23.07.2012).

12. Silfen R, Hudson DA, McCulley S. Penile lengthening for traumatic penile amputation due to ritual circumcision: a case report. Ann Plas Surg. 2000;44(3):311-6.

13. Independent Online (IOL), South Africa, 8 July 2004 dated 21.07.2012. http://www.cirp.org/news/ sapa07-08-04/ (Accessed on 24.07.2012).

14. Meel BL Traditional male circumcision-related fatalities in the Mthatha area of South Africa. Med. Sci. Law 2010; 50(4):189-91.

15. The Mail \& Guardian ( $M \& G)$, Johannesburg, South Africa, Monday, 8 December 2003). http:/ /www. cirp.org/news/mailandguardian12-08-03/(Accessed 24.07.2012).

16. Daily Dispatch. East London, Eastern Cape Province, South Africa, 13 December 2005). http://www. cirp.org/news/dailydispatch12-13-05/(Accessed 24.07.2012). 